\title{
Use of Noninvasive Ventilation During Feeding Tube Placement
}

\author{
Paolo Banfi MD, Eleonora Volpato MSc, Chiara Valota MSc, Salvatore D’Ascenzo, \\ Chiara Bani Alunno, Agata Lax MD, Antonello Nicolini MD, Nicola Ticozzi MD, \\ Vincenzo Silani MD, and John R Bach MD
}

\author{
Introduction \\ Methods \\ Literature Search Strategy \\ Inclusion and Exclusion Criteria \\ Study Selection \\ The Interventions \\ Data Extraction and Coding \\ Risk of Bias Assessment \\ Methodological Quality \\ Description of Studies \\ Clinical Implications \\ Limitations \\ Summary
}

Parenteral nutrition is indicated in amyotrophic lateral sclerosis (ALS) when dysphagia, loss of appetite, and difficulty protecting the airways cause malnutrition, severe weight loss, dehydration, and increased risk of aspiration pneumonia. The aim of this review is to compare percutaneous endoscopic gastrostomy (PEG), radiologically inserted G-tube (RIG), and percutaneous radiologic gastrostomy (PRG) in patients with ALS, performed with or without noninvasive ventilation (NIV). We searched PubMed, MEDLINE, EMBASE, the Cochrane Central Register of Controlled Trials (CENTRAL), the EBSCO Online Research Database, and Scopus up to December 2015. A priori selection included all randomized controlled trials (RCTs), quasi-randomized trials, and prospective and retrospective studies. The primary outcome was 30-d survival. We found no RCTs or quasi-RCTs. Seven studies about the implementation of the PEG/RIG procedure during the use of NIV and 5 studies without NIV were included. In another study of 59 subjects undergoing open gastrostomy, all with vital capacity $<30 \%$ of normal, 18 of whom were dependent on continuous NIV at full ventilatory support settings, there were no respiratory complications. Thus, the use of NIV during the implementation of these procedures, especially when used at full ventilatory support settings of pressure preset $18-25 \mathrm{~cm} \mathrm{H}_{2} \mathrm{O}$, can support alveolar ventilation before, during, and after the procedures and prevent respiratory complications. The procedures investigated appear equivalent, but the methodological quality of the studies could be improved. Possible benefits with regard to nutrition parameters, quality of life, and psychological features need to be further investigated. Key words: amyotrophic lateral sclerosis (ALS); noninvasive ventilation (NIV); gastrostomy; clinical effectiveness; quality of life $(Q O L)$; systematic review. [Respir Care 2017;62(11):1474-1484. (C) 2017 Daedalus Enterprises] 


\section{Introduction}

Amyotrophic lateral sclerosis (ALS) is a neurological disorder characterized by a progressive degeneration of the motor neurons. Bulbar onset affects $25-30 \%$ of all patients, but all patients surviving long enough eventually develop severe bulbar-innervated muscle impairment that causes dysphagia, aspiration of food and saliva, and severe dysarthria. ${ }^{1,2}$ Dysphagia causes malnutrition, dehydration, weight loss, and an increased risk of aspiration pneumo$\mathrm{nia}^{3}$ and is an important negative prognostic factor in ALS. ${ }^{4}$ Moreover, poor appetite due to depression, reduced ability to feed oneself, and hypermetabolism can also lead to decreased oral feeding and subsequent malnutrition/dehydration. ${ }^{5}$ Malnutrition increases muscle weakness, increases fatigue, ${ }^{6}$ and decreases respiratory capacity. ${ }^{7}$ This situation creates a vicious cycle, leading to the development of depression and decreasing quality of life (QOL). ${ }^{8}$ Dietary changes are thus necessary to maintain proper caloric intake and prevent aspiration. ${ }^{9,10}$ When oral feeding becomes insufficient, enteral nutrition in patients with ALS can be guaranteed through gastrostomy placement. The procedures include percutaneous endoscopic gastrostomy (PEG), radiologically inserted G-tube (RIG), percutaneous radiologic gastrostomy (PRG), and open gastrostomy. ${ }^{11,12} \mathrm{Al}-$ though percutaneous gastrostomy procedures are more frequently employed than those requiring general anesthesia, ${ }^{13}$ the frequency of PEG/RIG/PRG insertion varies widely across different countries and studies. ${ }^{9}$ To prevent and manage respiratory symptoms, the use of noninvasive ventilation (NIV), which has become synonymous with CPAP and low span $\left(<10 \mathrm{~cm} \mathrm{H}_{2} \mathrm{O}\right)$ bi-level PAP, is being used during the insertion of feeding tubes for many pa-

Dr Banfi, Ms Volpato, Mr D'Ascenzo, Ms Alunno, and Dr Lax are affiliated with the IRCCS Fondazione Don Carlo Gnocchi, Milan, Italy. Ms Volpato and Ms Valota are affiliated with the Department of Psychology, Università Cattolica del Sacro Cuore, Milan, Italy. Dr Nicolini is affiliated with the Respiratory Rehabilitation Unit, ASL 4 Chiavarese, Hospital of Sestri Levante, Italy. Drs Ticozzi and Silani are affiliated with the Unit of Neurology and Laboratory of Neuroscience, Istituto Auxologico Italiano, Istituto di Ricovero e Cura a Carattere Scientifico and the Department of Pathophysiology and Transplantation, Dino Ferrari Center, Università degli Studi di Milano, Milan, Italy. Dr Bach is affiliated with the Department of Physical Medicine and Rehabilitation, Rutgers University-New Jersey Medical School, Newark, New Jersey.

Supplementary material related to this paper is available at http:// www.rcjournal.com.

The authors have disclosed no conflicts of interest.

Correspondence: Banfi Paolo MD, Fondazione Don Carlo Gnocchi, HD Respiratory Rehabilitation Unit, Via Capecelatro, 66-CAP, 20149 Milan, Italy. E-mail: pabanfi@dongnocchi.it.

DOI: $10.4187 /$ respcare. 05031 tients with FVC $<50 \%$ of predicted normal. ${ }^{14}$ It should be noted, however, that in many centers, patients become dependent on continuous NIV at full ventilatory support settings. They require either high span $\left(15-25 \mathrm{~cm} \mathrm{H}_{2} \mathrm{O}\right)$ bi-level PAP or intermittent positive-pressure ventilation at full ventilatory support settings, delivered via noninvasive oral, nasal, or oronasal interfaces. Generally, portable ventilators are used with active circuits on volume control mode with exhaled tidal volume $>800 \mathrm{~mL}$ or pressure preset at 17$25 \mathrm{~cm} \mathrm{H}_{2} \mathrm{O} .{ }^{15}$ Many of these patients do not undergo gastrostomy until their vital capacities (VCs) are $<10 \%$ of predicted normal. ${ }^{15}$

There is no consistent evidence about which of the procedures is the safest and most effective in ALS. Although literature concerning RIG/PRG and open gastrotomies is scarce, frequency of PEG in patients with ALS, which was only around $2.7 \%$ in the early $1970 \mathrm{~s},{ }^{16}$ has more recently increased. ${ }^{12}$ Indeed, it has been performed on $13-40 \%$ of patients with ALS in the United States, ${ }^{17,18} 14-38 \%$ in the United Kingdom, ${ }^{19,20} 11-24 \%$ in Italy, ${ }^{21-23} 21-60 \%$ in Japan, ${ }^{9,24}$ and $20 \%$ in Canada. ${ }^{25}$ Meanwhile, the apparent increasing demand for RIG/PRGs and their possible advantages and disadvantages compared with PEGs in maintaining adequate nutrition and weight stabilization have not been assessed systematically and remain unclear. ${ }^{14,26}$ To the best of our knowledge, there has been only a single attempt to provide the best evidence to support procedures for parenteral nutrition, and it only compared PEG tube feeding with oral feeding for patients with ALS. ${ }^{9}$ The main aim of this review is to compare PEG, RIG, and PRG, with and without NIV use, for efficacy and safety.

\section{Methods}

\section{Literature Search Strategy}

The primary literature search method employed PubMed, MEDLINE, EMBASE, the Cochrane Central Register of Controlled Trials (CENTRAL), the EBSCO Online Research Database, and Scopus. The search strategy used a combination of subject heading terms appropriate for each database and key words such as "amyotrophic lateral sclerosis," "ALS," "noninvasive ventilation," "NIV," "gastrostomy," "feeding tube," "procedure," "placement," "percutaneous endoscopic gastrostomy," "PEG," "percutaneous radiologic gastrostomy," "PRG," "radiologically inserted G-tube," and "RIG" with Boolean terms such as AND and OR. These words were searched for in the title, abstract, key words, and MeSH (medical subject headings) terms. The reference lists of all eligible trials were checked, and the Cited By research tool was used. Findings were limited to English language and to human studies between 1980 and 2015. No unpublished studies or gray literature were considered (Fig. 1). 


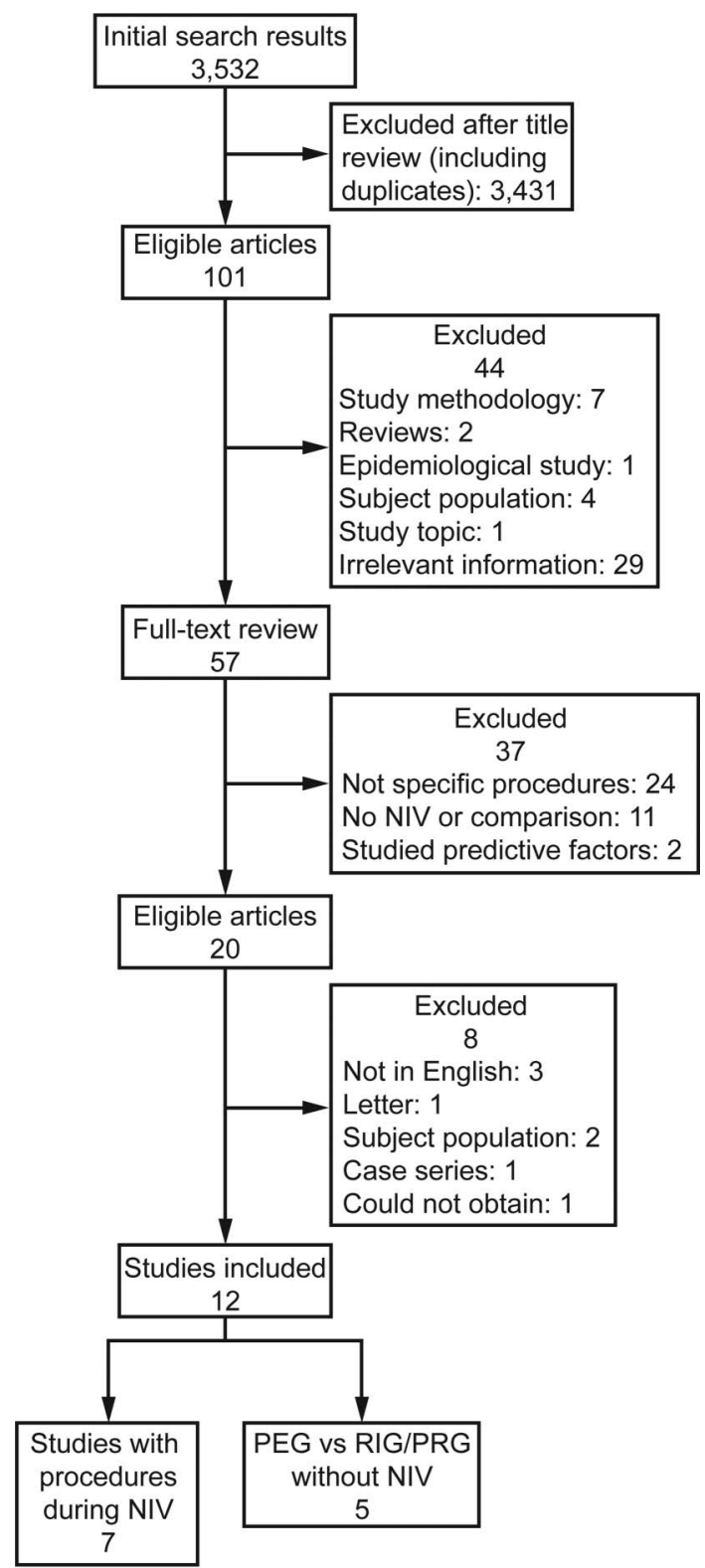

Fig. 1. Flow chart. NIV = noninvasive ventilation; $P E G=$ percutaneous endoscopy gastrostomy; RIG = radiologically inserted Gtube; $P R G=$ percutaneous radiologic gastrostomy.

\section{Inclusion and Exclusion Criteria}

Types of Studies. Before proceeding with the literature search, we defined the inclusion and exclusion criteria. We considered randomized controlled trials (RCTs), quasi-RCTs, prospective, and retrospective studies. Single cases, case series, and editorial letters were excluded from the data analysis.

Types of Participants. In-patients or day-hospital patients, diagnosed with definite, probable or possible ALS, according to El Escorial ${ }^{27}$ and revised El Escorial criteria, ${ }^{28}$ were included.
Types of Intervention. The primary intervention explored was placement of PEG or RIG/PRG during the course of ALS. There were no publications found comparing other methods. Subjects who underwent gastrostomy while using NIV or not were also compared.

Types of Outcome Measures. Primary outcome was survival time at $30 \mathrm{~d}$ from time of placement of the feeding tube. Secondary outcomes were complications (ie, hemorrhage, aspiration pneumonia, infections), their frequency, and the rate of death during the feeding tube placement.

\section{Study Selection}

In the primary literature search, 3,532 potential articles were identified. Two authors independently evaluated the title and abstract of each study to determine whether it met the inclusion criteria and excluded 3,431 papers because they were duplicates. Whenever titles or abstracts appeared to be relevant, they examined the full text. Any disagreement on selection was discussed with a third author. In total, 44 articles were excluded because they cited PEG or RIG/PRG but did not explain the procedure placement or excluded due to irrelevance of information and an absence of methodology. Additionally, 3 studies were excluded because they were not in English, one was not obtainable, and 4 did not meet the inclusion criteria (Fig. 1). In conclusion, this review included 5 studies comparing 2 or more feeding tube placements without NIV and 7 studies where the same procedures were used with NIV.

All of the included studies met the 3 key criteria, as required by the Cochrane Effective Practice and Organisation of Care Group (EPOC Review Group) for Control Before and After Studies. They include at least 2 intervention sites and 2 control sites (Table 1). Similarly, the pre- and the post-timing of the intervention groups are the same, and the 2 groups are comparable on key characteristics. ${ }^{29}$

\section{The Interventions}

The main features of the procedures as described in the studies are briefly illustrated below.

Percutaneous Endoscopic Gastrostomy. An endoscope is inserted down the esophagus into the stomach, under topical anesthesia with lidocaine or a derivative product. Sedation is not offered routinely, and, when present, midazolam $(2.5-5 \mathrm{mg})$ or fentanyl $(0.1 \mathrm{mg})$ is used. The light at the tip of the tube shines through the stomach and skin, directing the surgeon to the spot where the PEG tube should be inserted. The surgeon makes a small incision through the skin and the wall of the stomach and inserts the PEG 
Table 1. List of Principle Inclusion Criteria

\begin{tabular}{|c|c|}
\hline Study Characteristics & Inclusion Criteria \\
\hline Study design & $\begin{array}{l}\mathrm{RCT} \text {, quasi-RCT, prospective, and } \\
\text { retrospective }\end{array}$ \\
\hline Period & 1980-2015 \\
\hline Language & English \\
\hline Participants & $\begin{array}{l}\text { Definite, possible, or probable ALS, } \\
\text { according to El Escorial and revised } \\
\text { El Escorial criteria }\end{array}$ \\
\hline Condition & In-patients or day-hospital patients \\
\hline Interventions & $\begin{array}{l}\text { PEG/RIG/PRG during the use of NIV vs } \\
\text { PEG/RIG/PRG without NIV }\end{array}$ \\
\hline Primary outcomes & Survival time at $30 \mathrm{~d}$ \\
\hline Secondary outcomes & $\begin{array}{l}\text { Complications and their frequency rate; } \\
\text { death }\end{array}$ \\
\hline $\begin{array}{l}\mathrm{RCT}=\text { randomized controlle } \\
\mathrm{ALS}=\text { amyotrophic lateral } \\
\mathrm{PEG}=\text { percutaneous endosco } \\
\mathrm{RIG}=\text { radiologically insertec } \\
\mathrm{PRG}=\text { percutaneous radiolo } \\
\mathrm{NIV}=\text { noninvasive ventilatio }\end{array}$ & stomy \\
\hline
\end{tabular}

tube through it. Once the PEG tube has been inserted, the endoscope is removed.

Radiologically Inserted G-Tube. A nasogastric tube is inserted into the nose and directed into the stomach to insufflate it. It is removed immediately after the procedure is terminated. A RIG tube is inserted with the aid of fluoroscopy for the interventional radiologist to view realtime images of the patient's internal organs to find the right spot to insert the tube through the skin into the stomach (this is the main difference from the PRG procedure). To help to identify and avoid the intestines, barium is given the night before. A gastroplexy is held in place with sutures called T-tacs that are removed about $14 \mathrm{~d}$ after the RIG.

Percutaneous Radiologic Gastrostomy. A nasogastric tube is placed shortly before the procedure to insufflate the stomach. Local analgesia and sedation may or may not be used. Joshine N-butyl-bromide ( $5 \mathrm{mg}$ intravenously) is administered to reduce gastric motility and for adequate distention, thus decreasing the risk of puncture of colon, liver, and other organs. With the patient supine, fluoroscopy of the abdomen is undertaken, and the position of the nasogastric tube is identified. A site for gastric puncture is chosen equidistant from the greater and lesser curves of the stomach. The needle is inserted into the air-filled stomach under fluoroscopic guidance. Aspiration of air bubbles into the syringe confirms intragastric positioning of the needle. Normally, a 12 French polyurethane tube is used and fixed by means of a loop. During the first day after the procedure, the patients receive only parenteral nutrition.
During the entire procedure, NIV users are administered NIV generally via a nasal interface.

Percutaneous Endoscopic Gastrostomy During NIV in Our Experience. A respiratory therapist trains NIV-naïve patients in NIV via nasal and nasal prong interfaces before the procedures. There are at least 5 training sessions in the patients' homes, at the clinic, or at the hospital as they prefer. Its effectiveness is assessed by ambient air $\mathrm{O}_{2}$ saturation monitoring and patient acceptance. The respiratory therapist guides the patient to the endoscopy unit, where sedation with local anesthesia with $2.5 \mathrm{mg}$ of midazolam is initiated, and biological variables, such as $\mathrm{S}_{\mathrm{pO}_{2}}$, heart rate, breathing frequency, and blood pressure, are constantly monitored. During the entire procedure, the respiratory therapist sustains the patients on NIV via nasal interface or nasal prongs. No study comparisons were found for per-oral image-guided gastrostomy or for open gastrostomy.

\section{Data Extraction and Coding}

Two authors independently extracted data according to the inclusion criteria. Data included year, country, study design, site of onset of ALS, NIV, CoughAssist (Respironics, Murrysville, Pennsylvania) use, type of NIV interface, procedure of feeding tube placement, use of sedation, sex, number of subjects, mean age, measuring tools, dropout rate, exclusion criteria, and main findings. The principal statistical analyses were annotated. Nutritional markers, such as body mass index, hemoglobin, and serum albumin level, were also evaluated. QOL as measured by validated instruments was recorded as well. Finally, the rate of complications and types of adverse events, both during and after the procedures, were reviewed.

\section{Risk of Bias Assessment}

No RCTs were identified. Therefore, there was insufficient detail to make a judgment, using the assessment tool of the Cochrane Collaboration. ${ }^{30}$ However, 2 authors independently attempted to obtain an overall description of the body of evidence to integrate it into a narrative synthesis as the EPOC Review Group suggests. ${ }^{29}$ None of the trials reported methods of both random sequence generation and allocation concealment of the patients recruited.

The death and complication rates were uniformly reported except in 2 studies. ${ }^{31,32}$ The dropout rate was not specified. Additionally, none of the studies was blinded due to the intervention itself. The follow-up time-points were only specified in one study. ${ }^{33}$ In the other studies, the evaluations at 20-30 d before and after the procedure were noted but there was no further follow up. Finally, the integrity of the study designs was limited due to the lack 
of randomization, a task that would have been extremely difficult to accomplish for both ethical and clinical reasons.

\section{Methodological Quality}

The Newcastle-Ottawa Quality Assessment Scale was used to evaluate the methodological quality of the cohort, case-control, and prospective or retrospective studies included. ${ }^{34}$ According to this checklist, the required independent validation was guaranteed in every study. The representativeness of the cases and the selection and definition of controls were present in each study that considered the use of NIV. However, these items did not fully satisfy requirements, nor were there statements or descriptions about them. The comparability of controls was well or partly stated in the majority of the included studies, except for one. Determination of exposure was adequate; on the contrary, follow-ups and non-response rate were either not reported or were poorly described.

\section{Description of Studies}

After eligibility assessment, 20 articles were evaluated. Among these, 12 studies were included in the qualitative synthesis. In particular, 7 studies were about PEG or PRG procedures during NIV, whereas the other 5 focused on the comparison of PEG and RIG/PRG without NIV during the procedure (see supplementary Tables 1 and 2 at http:// www.rcjournal.com). Controlled studies that considered the outcomes of interest are reported in the following sections.

\section{Included Studies}

Not all of the required data were available in the studies, but they had to be extrapolated from the text if relevant to the primary outcomes (ie, mortality, adverse events). In addition, although we found no open gastrostomy studies that compared efficacy with other methods, the fact that 18 were performed on continuous NIV-dependent subjects before, during, and after gastrostomy is important to point out.

\section{Study Design and Participants}

We identified 3 prospective studies, 7 retrospective studies, and 2 cohort studies. Among these, 4 studies considered the PEG placement during NIV, and 5 evaluated the same procedure without NIV. Moreover, 7 studies were based on RIG/PRG, of which 2 discussed the use of NIV and 5 were performed without it.

The overall number of participants was 804 (mean \pm SD age $=62.53 \pm 0.22 \mathrm{y}$ ). Among them, 258 subjects used
NIV during the tube placement procedure, whereas 546 subjects did not. Among those who used NIV during the tube placement, 25 subjects were ongoing NIV users for $11 \pm 5.6 \mathrm{~h} / \mathrm{d},{ }^{35} 19$ subjects for $>4 \mathrm{~h} / \mathrm{d},{ }^{32}$ and 5 subjects for a mean of $5 \pm 3.3 \mathrm{~h} / \mathrm{d} .{ }^{3}$ In 2 other studies, 17 and 81 subjects used NIV without indication of daily hours of use. ${ }^{31,33}$ In 3 other studies, there was no information concerning NIV utilization, ${ }^{36}$ nor was it clear whether it was used routinely and/or during the PEG/RIG/PRG procedure. ${ }^{37,38}$ The most common inclusion criteria for each study were diagnoses of amyotrophic lateral sclerosis according to El Escorial criteria, dysphagia, nutritional intake, weight loss of $>5-10 \%$, FVC $<50 \%$, the ability to cooperate and give consent, and aspiration.

\section{Primary Outcomes}

In only one study was survival at $30 \mathrm{~d}$ explicitly described as the primary outcome, ${ }^{33}$ whereas in the other cases, it was a secondary outcome. The overall mean survival at $30 \mathrm{~d}$ is shown in Table 2 (see supplementary Tables 3 and 4).

\section{Secondary Outcomes}

All complications were clearly detailed except in 2 studies. ${ }^{31,32}$ The major complications were (Table 3) respiratory decompensation, local wound infections, peritonitis, pneumoperitoneum, perigastrostomy tube leakage, and post-procedure pain.

The minor complications were disturbances of intestinal transit (diarrhea, vomiting, constipation), laryngospasm, upper-respiratory tract infection, G-tube site cellulitis and minor bleeding at the G-tube site, mechanical obstruction caused by tube migration, difficulty penetrating the gastric mucosa, transient hypoxia, agitation, and dislodged tooth crown. Death rates during the procedure were not indicated.

In one of our centers, 79 ALS subjects underwent gastrostomy from September 1, 2012, to December, 31, 2015, and the 30-d survival was recorded. PEG during NIV was complicated by desaturation ( 2 cases), which resolved by increasing the NIV settings, and by gastric hemorrhage, which resolved with embolization (one case).

\section{Study Comparisons}

In 7 studies, the interventions considered were PEG (5 studies) and PRG (2 studies) during the use of NIV. In 5 studies, the interventions were PEG versus PRG or RIG without NIV. Follow-up times varied across the different studies. Only a single study specified the major time points as follows: time of recruitment, end of gastrostomy procedure, and 3- and 12-month follow-up. However, there 
Table 2. Overall Mean Survival at 30 Days From the Procedure*

\begin{tabular}{|c|c|c|c|c|c|c|c|}
\hline \multirow{3}{*}{ Study (Year) } & \multicolumn{3}{|c|}{ PEG/RIG/PRG with NIV } & \multirow{3}{*}{ Study (Year) } & \multicolumn{3}{|c|}{ PEG vs RIG/PRG without NIV } \\
\hline & \multirow{2}{*}{$\begin{array}{c}\text { Total } \\
\text { subjects, } N\end{array}$} & \multicolumn{2}{|c|}{ Survival at $30 \mathrm{~d}$} & & \multirow{2}{*}{$\begin{array}{c}\text { Total } \\
\text { subjects, } N\end{array}$} & \multicolumn{2}{|c|}{ Survival at $30 \mathrm{~d}$} \\
\hline & & Survivors, $n$ & Died $(\%)$ & & & Survivors, $n$ & Died $(\%)$ \\
\hline Sancho et $\mathrm{al}^{35}$ (2010) & 30 & 30 & 0 & Thornton et al ${ }^{39}$ (2002) & 36 & 34 & 5.5 \\
\hline Gregory et al ${ }^{32}$ (2002) & 33 & 31 & 6.1 & Miller et al ${ }^{40}$ (2013) & 108 & 106 & 1.9 \\
\hline Rio et $\mathrm{al}^{36}(2005)$ & 64 & 58 & 17 & Desport et $\mathrm{al}^{41}(2005)$ & 50 & Not present & 23.4 \\
\hline Chiò et $\mathrm{al}^{3}$ (2004) & 50 & 48 & 4 & Blondet et $\mathrm{al}^{42}(2010)$ & 43 & Mortality rates $9.3 \%$ & 9.3 \\
\hline Sarfaty et $\mathrm{al}^{31}$ (2013) & 30 & 28 & 6.7 & ProGas Study Group ${ }^{33}$ (2015) & 330 & 318 & 3.6 \\
\hline Park and Kang ${ }^{37}$ (2009) & 25 & 25 & 0 & & & & \\
\hline Czell et al ${ }^{38}$ (2013) & 26 & 25 & 3.8 & & & & \\
\hline Mean & 36.9 & 35 & 5.4 & Mean & 113.4 & $152.67 * *$ & 8.7 \\
\hline
\end{tabular}

Table 3. General Illustration of Major and Minor Complications of the Studies Included

\begin{tabular}{|c|c|c|c|}
\hline \multicolumn{2}{|c|}{ PEG or RIG/PRG with NIV } & \multicolumn{2}{|c|}{ PEG vs RIG/PRG without NIV } \\
\hline Major Complications & Minor Complications & Major Complications & Minor Complications \\
\hline Local wound infections $s^{35,37}$ & Laryngospasm $^{38}$ & Respiratory decompensation ${ }^{40,42}$ & $\begin{array}{l}\text { Problem of intestinal transit (diarrhea, } \\
\text { vomiting, constipation) })^{33,40,41}\end{array}$ \\
\hline Peritonitis $^{38}$ & Upper-respiratory tract infection ${ }^{35,38}$ & Peritonitis ${ }^{39}$ & Laryngospasm $^{33}$ \\
\hline Post-procedure pain ${ }^{32}$ & $\begin{array}{l}\text { G-tube site cellulitis and minor } \\
\text { bleeding at the G-tube site }{ }^{37}\end{array}$ & Post-procedure pain ${ }^{33,40-42}$ & $\begin{array}{l}\text { G-tube site cellulitis and minor } \\
\text { bleeding at the G-tube site }{ }^{33,40}\end{array}$ \\
\hline Pneumoperitoneum ${ }^{37}$ & $\begin{array}{l}\text { Rarely of mechanical obstruction } \\
\text { caused by tube migration }\end{array}$ & Local wound infections ${ }^{33,42}$ & $\begin{array}{l}\text { Rarely of mechanical obstruction } \\
\text { caused by tube migration }{ }^{41}\end{array}$ \\
\hline \multirow[t]{4}{*}{$\begin{array}{l}\text { Perigastrostomy tube } \\
\text { leakage }^{37}\end{array}$} & Dislodged tooth crown ${ }^{3}$ & & $\begin{array}{l}\text { Difficulty to penetrate the gastric } \\
\text { mucosa }^{40}\end{array}$ \\
\hline & & & Transient hypoxia ${ }^{40}$ \\
\hline & & & Agitation $^{33,40-42}$ \\
\hline & & & Dislodged tooth crown ${ }^{40}$ \\
\hline \multicolumn{4}{|c|}{$\overline{\mathrm{PEG}=\text { percutaneous endoscopic gastrostomy }}$} \\
\hline \multicolumn{4}{|c|}{$\mathrm{RIG}=$ radiologically inserted G-tube } \\
\hline \multirow{2}{*}{\multicolumn{4}{|c|}{ PRG $=$ percutaneous radiologic gastrostomy }} \\
\hline & & & \\
\hline
\end{tabular}

were no 3- and 12-month data. ${ }^{33}$ The other studies stressed the importance of evaluation 20-30 d before and after the intervention but did not report long-term follow-up. Only a single study reported the effects of PRG, noting that it was a minor procedure, its shorter duration, and the fact that sedation was not required. ${ }^{3}$

PEG and RIG or PRG were all noted to have high long-term success rates and low mortality, morbidity, and stress for patients. ${ }^{39,43}$ However, it is important to note that survival is more linked to the ALS progression than to the method of gastrostomy ${ }^{42}$ (see supplementary Tables 5 and 6). Complications and survival were not shown to be significantly different for PEG or RIG. ${ }^{8}$ However, the videofluoroscopy study by Desport et $\mathrm{al}^{41}$ showed that aspiration was higher in subjects who underwent a RIG compared with those who had a PEG, as suggested by a 2015 case study. ${ }^{44}$

\section{Safety and Timing}

None of the studies provided specific recommendations for timing PEG or RIG/PRG in subjects with ALS. According to the American Academy of Neurology, choking, weight loss, dehydration, dysphagia, and aspiration must be considered. ${ }^{45}$ PEG or RIG/PRG can stabilize weight and facilitate medication administration. ${ }^{46}$ Conventional criteria for gastrostomy have included FVC $<50 \% 47,48$; weight loss $>10 \%$ from premorbid weigh; severe dysphagia, even in the absence of formal scales to evaluate its severity; and severe aspiration. Although the use of NIV 
and FVC $<50 \%$ were considered important inclusion criteria in 2 studies, ${ }^{35,37}$ the fact that 59 open gastrostomies were performed on subjects with VCs $<30 \%$ of normal, including 18 who had no ventilator-free breathing ability before, during, or after gastrostomy and had no respiratory complications at all from the procedure, indicates that when full ventilator setting noninvasive ventilatory support is used along with mechanical in-exsufflation to clear airway secretions as needed, gastrostomy can be performed safely irrespective of residual respiratory function. ${ }^{11}$ Indeed, in a multi-center study of 355 continuous noninvasive ventilatory support-dependent ALS subjects, all 74 who underwent tracheostomy after a mean of $1.2 \mathrm{y}$ of continuous noninvasive ventilatory support had to undergo gastrotomies despite having VCs $<10 \%$ and no autonomous breathing ability. ${ }^{16}$ Thus, whereas the implementation of NIV as lowlevel bi-level PAP during PEG or RIG/PRG can prevent respiratory failure during the procedure for relatively mild non-continuous noninvasive ventilatory support-dependent patients, full settings of noninvasive ventilatory support are required for ventilator-unweanable continuous noninvasive ventilatory support users as well as for others who have VCs $<30 \%$ of normal, for safety. ${ }^{37}$ None of the studies reviewed reported using full setting noninvasive ventilatory support during the PEG or RIG/PRG procedures. Their use of NIV during the procedures, however, is compared with baseline pre-intervention use of NIV in Table $4 .{ }^{49}$

\section{Clinical Implications}

The nutritional advantages of all of the studied procedures in ALS are clear, as is the positive effect on QOL of patients by avoiding starvation. However, PEG placement may be initiated too early by clinicians unfamiliar with noninvasive ventilatory support and the use of mechanical in-exsufflation to clear airway debris perioperatively ${ }^{11,51}$ and, therefore, is possibly associated with higher complication rates. ${ }^{14,50,52}$

The studies reviewed did not shed light on the relative desirability of one intervention over another either perioperatively or long-term. Also, the studies provide no evidence for precise timing of the PEG or RIG/PRG in patients with ALS. Controversy concerning the initiation of parenteral nutrition is complicated by the fact that the underlying pathology causes protein catabolism hypermetabolism. ${ }^{46}$

The importance of noninvasive ventilatory support and mechanical in-exsufflation during the PEG/RIG/PRG procedures was made clear by Allen et al., who explained that respiratory failure occurred in 4 of their subjects in which gastrostomy placement was delayed without NIV, 54 whereas open gastrostomies on continuous noninvasive ventilatory support-dependent patients, including many with ALS, have been performed on patients with VC $<10 \%$ with no respiratory complications. ${ }^{11,12}$ However, there are no controlled studies regarding NIV use for these procedures. To achieve this aim, an RCT might be carried out, but this would likely be unethical. RCTs comparing gastrostomy with starvation would be unethical. Although the use of NIV/noninvasive ventilatory support during feeding tube placement is becoming the standard for best practice, it was not done in these studies. Switching from nasal to oronasal interface is essentially switching from an open to a closed system of ventilatory assistance/support. Possible hypoventilation during the procedures could have been conveniently monitored by end-tidal or transcutaneous $\mathrm{CO}_{2}$ and $\mathrm{O}_{2}$ saturation monitoring. If supplemental $\mathrm{O}_{2}$ is avoided, then $\mathrm{O}_{2}$ saturation $>95 \%$ can signal significant hypercapnia as well. Hypoventilation can be resolved by increasing nasal ventilation settings and keeping the lips closed or by passing endoscopy tubes via a hole in an oronasal interface used to provide full noninvasive ventilatory support.

Few centers are experienced using continuous noninvasive ventilatory support and mechanical in-exsufflation to prevent respiratory complications. ${ }^{48}$ Without perioperative continuous NIV and mechanical inexsufflation support for patients with very low VCs, the fact that far less than 50\% of conventionally managed ALS subjects cited in the studies reviewed underwent gastrostomy, suggests that many patients who do not as yet have sufficiently severe bulbarinnervated muscle dysfunction to require the procedure may be dying from ventilatory failure because they are not placed on continuous NIV. ALS patients require tracheostomy only when bulbar innervated muscle dysfunction is due to upper motor neuron or CNS pathology and not lower motor neuron or myopathic. ${ }^{55,56}$ The patients, are, therefore, dying prematurely. Thus, the use of FVC $<50 \%$ as an indication for gastrostomy remains controversial. Some authors suggest a figure of $65-70 \%$ or, alternatively, that gastrostomy can be done safely for ALS patients with FVC $<10 \%$ and severe dysphagia of primarily lower motor neuron pathology. ${ }^{55,56}$

\section{Limitations}

The effects of PEG or RIG/PRG procedures on both patients and their caregivers and their health-related QOL were not well investigated. It would have been useful to have explored the patients' perspective on the procedures, from the decision making process to the changes in their daily lives, to understand better how to support them and their caregivers.

None of the studies included is an RCT or a quasi-RCT. This reduced the possibility of comparing the efficacy of the procedures studied especially in quantitative terms. All of the studies had potential selection and confounding biases and selective reporting of outcomes. 


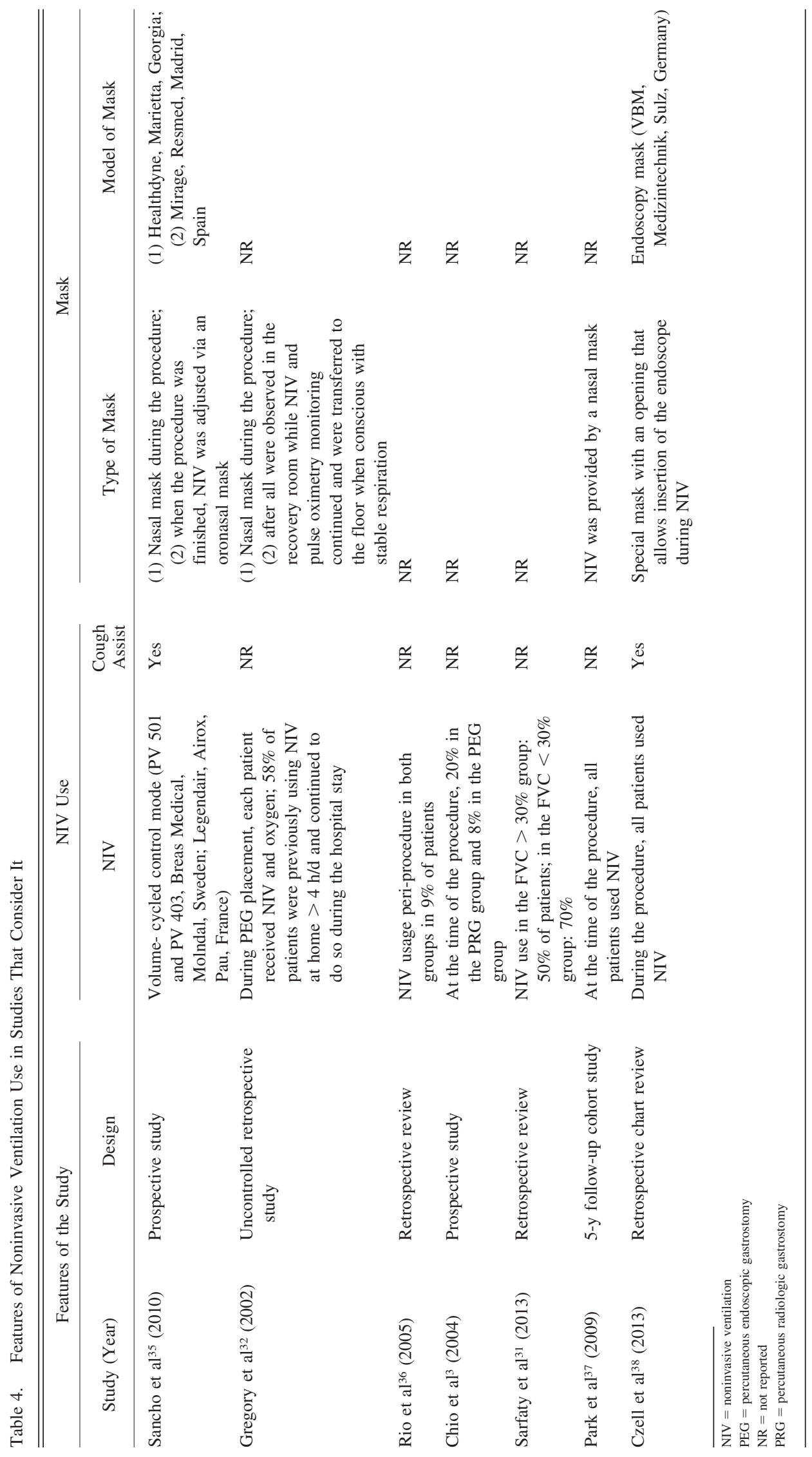


All of the studies claimed the importance of an evaluation 20-30 d before and after the intervention, but only one of them specified the importance a longer follow-up time without indicating the data. ${ }^{34}$ Long term follow-up might have revealed complications specific to one intervention over another, such as possibly greater risk of reflux following RIG. Moreover, in the studies included, the dropout rate was not considered, or it was explained unsatisfactorily, and the weight change from baseline was not indicated.

Studies have shown that facing decisions during emergency hospital admissions or having the opportunity to carefully evaluate information over time can elicit different feelings and beliefs both in patients and caregivers. ${ }^{53}$ According to the guidelines of the European Federation of Neurological Societies, patients and caregivers should be informed about both benefits and risks of the proposed procedure as well as the possibility of relying on oral intake for as long as is feasible and informed that postponing the PEG/PRG or RIG procedure could increase the respiratory risk by permitting increased aspiration of food and saliva and insidiously progressive malnutrition common in patients with ALS. ${ }^{50}$ In addition, the occurrence of cognitive and behavioral symptoms belonging to the frontotemporal dementia spectrum and their repercussions on the decision-making processes toward the PEG or RIG/PRG procedure in patients with ALS have not been considered, with the exception of the study by Allen et al. ${ }^{54}$ However, in this study, formal cognitive testing was not performed, and the physicians considered it present if documented in the clinical records..$^{54}$

Although the American Academy of Neurology disseminated one of the few practice guidelines concerning PEG, affirming that it is needed when there is evidence of accelerated weight loss and severe dysphagia, ${ }^{41,46}$ none of the studies included in this work have the same point of view on this, nor have they adopted the same approaches for placing gastrostomies. Finally, none of the studies evaluated cost-effectiveness. Knowing the insertion costs could be helpful to evaluate the advantages of a PEG or RIG/PRG.

\section{Summary}

There are various methods of feeding tube insertion, but PEG continues to be considered the accepted standard for gastrostomy and is the most commonly used method in patients with ALS. However, the indication for and timing of gastrostomy are controversial. Some suggest that it be considered at the onset of NIV usage, others that only dysphagia severity and its upper vs. lower motor neuron nature be considered. Indeed, whereas many non-bulbar ALS patients have severe respiratory orthopnea and require noninvasive ventilatory support to sleep reclining, they often have no bulbarinnervated muscle involvement at all at this point and eat and protect their airways without any difficulty. Thus, the initiation of NIV in non-bulbar patients should not be an indication for gastrostomy. With optimal noninvasive respiratory management, basing gastrostomy on dysphagia alone may be the most appropriate recommendation.

Future studies need to be more rigorous regarding internal validity and planned follow-up to compare both shortand long-term consequences of these various procedures not only for ALS, but for other diagnoses not so temporarily limited by the severe rapidly progressive pathology of ALS. Cost-effectiveness needs to be assessed as well as the use of noninvasive ventilation for not only symptom management but for ventilatory support as well.

\section{REFERENCES}

1. Beghi E, Millul A, Logroscino G, Vitelli E, Micheli A, SLALOM GROUP. Outcome measures and prognostic indicators in patients with amyotrophic lateral sclerosis. Amyotroph Lateral Scler 2008; 9(3):163-167.

2. Banfi P, Ticozzi N, Lax A, Guidugli GA, Nicolini A, Silani V. A review of options for treating sialorrhea in amyotrophic lateral sclerosis. Respir Care 2015;60(3):446-454.

3. Chiò A, Galletti R, Finocchiaro C, Righi D, Ruffino MA, Calvo A, et al. Percutaneous radiological gastrostomy: a safe and effective method of nutritional tube placement in advanced ALS. J Neurol Neurosurg Psychiatry 2004;75(4):645-647.

4. Desport JC, Preux PM, Truong TC, Vallat JM, Sautereau D, Couratier P. Nutritional status is a prognostic factor for survival in ALS patients. Neurology 1999;53(5):1059-1059.

5. Desport JC, Preux PM, Magy L, Boirie Y, Vallat JM, Beaufrère B, Couratier P. Factors correlated with hypermetabolism in patients with amyotrophic lateral sclerosis. Am J Clin Nutr 2001;74(3):328334.

6. Jeejeebhoy K. Muscle function and nutrition. Gut 1986;27(Suppl 1):25-39.

7. Laaban JP, Kouchakji B, Dore MF, Orvoen-Frija E, David P, Rochemaure J. Nutritional status of patients with chronic obstructive pulmonary disease and acute respiratory failure. Chest 1993;103(5): 1362-1368.

8. Desport JC, Preux PM, Truong CT, Courat L, Vallat JM, Couratier P. Nutritional assessment and survival in ALS patients. Amyotroph Lateral Scler Other Motor Neuron Disord 2000;1(2):91-96.

9. Katzberg HD, Benatar M. Enteral tube feeding for amyotrophic lateral sclerosis/motor neuron disease. Cochrane Database Syst Rev 2011;(1):CD004030.

10. Körner S, Hendricks M, Kollewe K, Zapf A, Dengler R, Silani V, Petri S. Weight loss, dysphagia and supplement intake in patients with amyotrophic lateral sclerosis (ALS): impact on quality of life and therapeutic options. BMC Neurol 2013;13:84.

11. Sharma A, Bach JR, Swan KG. Open gastrostomy under local anesthesia for patients with neuromuscular disorders. Am Surgeon 2010; 76(4):369-371.

12. Bach JR, Gonçalves MR, Hamdani I, Winck JC. Extubation of unweanable patients with neuromuscular weakness: a new management paradigm. Chest 2010;137(5):1033-1039.

13. Galletti R, Finocchiaro E, Repici A, Saracco G, Zanardi M. Comparison of complication rates between endoscopic and fluoroscopic percutaneous gastrostomies. Nutrition 2001;17(11):967-968.

14. Kasarskis EJ, Scarlata D, Hill R, Fuller C, Stambler N, Cedarbaum JM. A retrospective study of percutaneous endoscopic gastrostomy 


\section{FEEding With AND Without NIV IN ALS}

in ALS patients during the BDNF and CNTF trials. J Neurol Sci 1999;169(1):118-125.

15. Bach JR, Gonçalves MR, Hon A, Ishikawa Y, De Vito EL, Prado F, Dominguez ME. Changing trends in the management of end-stage respiratory muscle failure in neuromuscular disease: current recommendations of an international consensus. Am J Phys Med Rehabil 2013;92(3):267-277.

16. Jokelainen M. Amyotrophic lateral sclerosis in Finland. Acta Neurol Scand 1977;56(3):194-204

17. Bradley WG, Anderson F, Gowda N, Miller RG, ALS CARE Study Group. Changes in the management of ALS since the publication of the AAN ALS practice parameter 1999. Amyotroph Lateral Scler Other Motor Neuron Disord 2004;5(4):240-244.

18. Lechtzin N, Wiener CM, Clawson L, Chaudhry V, Diette GB. Hospitalization in amyotrophic lateral sclerosis: causes, costs, and outcomes. Neurology 2001;56(6):753-757.

19. Allison SP, Rawlings J, Field J, Bean N, Stephen AD. Nutrition in the elderly hospital patient Nottingham studies. J Nutr Health Aging 2000;4(1):54-57.

20. Neudert C, Oliver D, Wasner M, Borasio GD. The course of the terminal phase in patients with amyotrophic lateral sclerosis. J Neurol 2001;248(7):612-616.

21. Boitano LJ, Jordan T, Benditt JO. Noninvasive ventilation allows gastrostomy tube placement in patients with advanced ALS. Neurology 2001;56(3):413-414.

22. Chiò A, Mora G, Leone M, Mazzini L, Cocito D, Giordana MT, et al. Early symptom progression rate is related to ALS outcome: a prospective population-based study. Neurology 2002;59(1):99-103.

23. Mazzini L, Corrà T, Zaccala M, Mora G, Del Piano M, Galante M. Percutaneous endoscopic gastrostomy and enteral nutrition in amyotrophic lateral sclerosis. J Neurol 1995;242(10):695-698.

24. Seki H, Kameya T, Kimura I. [A survey of current nutrition therapy for the ALS patients in Japanese national sanatoriums]. Rinsho Shinkeigaku 2000;40(11):1083-1089.

25. Strong MJ, Rowe A, Rankin RN. Percutaneous gastrojejunostomy in amyotrophic lateral sclerosis. J Neurol Sci 1999;169(1):128-132.

26. Klor BM, Milianti FJ. Rehabilitation of neurogenic dysphagia with percutaneous endoscopic gastrostomy. Dysphagia 1999;14(3):162-164.

27. Brooks BR. El Escorial World Federation of Neurology criteria for the diagnosis of amyotrophic lateral sclerosis. J Neurol Sci 1994; 124(Suppl):96-107.

28. Brooks BR, Miller RG, Swash M, Munsat TL, World Federation of Neurology Research Group on Motor Neuron Diseases. El Escorial revisited: revised criteria for the diagnosis of amyotrophic lateral sclerosis. Amyotroph Lateral Scler Other Motor Neuron Disord 2000; 1(5):293-299.

29. Ryan R, Hill S, Prictor M, McKenzie J. Cochrane Consumers and Communication Review Group study quality guide: guide for review authors on assessing study quality. 2013. https://cccrg.cochrane.org/ sites/cccrg.cochrane.org/files/public/uploads/StudyQualityGuide_ May\%202013.pdf. Accessed June 15, 2017.

30. Higgins JP, Altman DG, Gøtzsche PC, Jüni P, Moher D, Oxman AD, et al. The Cochrane Collaboration's tool for assessing risk of bias in randomised trials. BMJ 2011;343:d5928.

31. Sarfaty M, Nefussy B, Gross D, Shapira Y, Vaisman N, Drory VE. Outcome of percutaneous endoscopic gastrostomy insertion in patients with amyotrophic lateral sclerosis in relation to respiratory dysfunction. Amyotroph Lateral Scler Frontotemporal Degener 2013; 14(7):528-532.

32. Gregory S, Siderowf A, Golaszewski AL, McCluskey L. Gastrostomy insertion in ALS patients with low vital capacity: respiratory support and survival. Neurology 2002;58(3):485-487.
33. ProGas Study Group. Gastrostomy in patients with amyotrophic lateral sclerosis (ProGas): a prospective cohort study. Lancet Neurol 2015;14(7):702-709.

34. Wells G, Shea B, O'Connell D. New Castle-Ottawa Quality Assessment Scale-Cohort Studies. 2010.

35. Sancho J, Servera E, Chiner E, Bañuls P, Gómez-Merino E, SanchoChust JN, Marín J. Noninvasive respiratory muscle aids during PEG placement in ALS patients with severe ventilatory impairment. J Neurol Sci 2010;297(1):55-59.

36. Rio A, Ampong MA, Turner MR, Shaw AS, Al-Chalabi A, Shaw CE, et al. Comparison of two percutaneous radiological gastrostomy tubes in the nutritional management of ALS patients. Amyotroph Lateral Scler Other Motor Neuron Disord 2005;6(3):177-181.

37. Park JH, Kang SW. Percutaneous radiologic gastrostomy in patients with amyotrophic lateral sclerosis on noninvasive ventilation. Arch Phys Med Rehabil 2009;90(6):1026-1029.

38. Czell D, Bauer M, Binek J, Schoch OD, Weber M. Outcomes of percutaneous endoscopic gastrostomy tube insertion in respiratory impaired amyotrophic lateral sclerosis patients under noninvasive ventilation. Respir Care 2013;58(5):838-844.

39. Thornton FJ, Fotheringham T, Alexander M, Hardiman O, McGrath FP, Lee MJ. Amyotrophic lateral sclerosis: enteral nutrition provision—endoscopic or radiologic gastrostomy? Radiology 2002;224(3): 713-717.

40. Miller RG, Rosenberg JA, Gelinas DF, Mitsumoto H, Newman D, Sufit R, et al. Practice parameter: the care of the patient with amyotrophic lateral sclerosis (an evidence-based review): report of the Quality Standards Subcommittee of the American Academy of Neurology. Neurology 1999;52(7):1311-1323

41. Desport JC, Mabrouk T, Bouillet P, Perna A, Preux PM, Couratier P. Complications and survival following radiologically and endoscopically-guided gastrostomy in patients with amyotrophic lateral sclerosis. Amyotroph Lateral Scler Other Motor Neuron Disord 2005; 6(2):88-93

42. Blondet A, Lebigot J, Nicolas G, Boursier J, Person B, Laccoureye L, Aubé, C. Radiologic versus endoscopic placement of percutaneous gastrostomy in amyotrophic lateral sclerosis: multivariate analysis of tolerance, efficacy, and survival. J Vasc Interv Radiol 2010; 21(4):527-533.

43. Pender SM, Courtney MG, Rajan E, McAdam B, Fielding JF. Percutaneous endoscopic gastrostomy-results of an Irish single unit series. Ir J Med Sci 1993;162(11):452-455.

44. Chesoni SA, Bach JR, Okamura EM. Massive reflux and aspiration following gastrostomy tube placement. Am J Phys Med Rehabil 2015;94(1):e6-e9.

45. Miller RG, Jackson CE, Kasarskis EJ, England JD, Forshew D, Johnston W, et al. Practice parameter update: the care of the patient with amyotrophic lateral sclerosis: drug, nutritional, and respiratory therapies (an evidence-based review): report of the Quality Standards Subcommittee of the American Academy of Neurology. Neurology 2009;73(15):1218-1226.

46. Löser C, Aschl G, Hébuterne X, Mathus-Vliegen EM, Muscaritoli $\mathrm{M}$, Niv $\mathrm{Y}$, et al. ESPEN guidelines on artificial enteral nutritionpercutaneous endoscopic gastrostomy (PEG). Clin Nutr 2005;24(5): 848-861.

47. Shaw AS, Ampong MA, Rio A, Al-Chalabi A, Sellars ME, Ellis C, et al. Survival of patients with ALS following institution of enteral feeding is related to pre-procedure oximetry: a retrospective review of 98 patients in a single centre. Amyotroph Lateral Scler Other Motor Neuron Disord 2006;7(1):16-21.

48. Heffernan C, Jenkinson C, Holmes T, Feder G, Kupfer R, Leigh PN, et al. Nutritional management in MND/ALS patients: an evidence based review. Amyotroph Lateral Scler Other Motor Neuron Disord 2004;5(2):72-83. 


\section{FEEding With AND Without NIV IN ALS}

49. EFNS Task Force on Diagnosis and Management of Amyotrophic Lateral Sclerosis, Andersen PM, Abrahams S, Borasio GD, de Carvalho $\mathrm{M}$, Chio $\mathrm{A}$, et al. EFNS guidelines on the clinical management of amyotrophic lateral sclerosis (MALS)-revised report of an EFNS task force. Eur J Neurol 2012;19(3):360-375.

50. Gonçalves MR, Honrado T, Winck JC, Paiva JA. Effects of mechanical insufflation-exsufflation in preventing respiratory failure after extubation: a randomized controlled trial. Crit Care 2012; 16(2):R48.

51. Silani V, Kasarskis EJ, Yanagisawa N. Nutritional management in amyotrophic lateral sclerosis: a worldwide perspective. J Neurol 1998; 245(Suppl 2):S13-S19.

52. Liley AJ, Manthorpe J. The impact of home enteral tube feeding in everyday life: a qualitative study. Health Soc Care Community 2003; 11(5):415-422.
53. Allen JA, Chen R, Ajroud-Driss S, Sufit RL, Heller S, Siddique T, Wolfe L. Gastrostomy tube placement by endoscopy versus radiologic methods in patients with ALS: a retrospective study of complications and outcome. Amyotroph Lateral Scler Frontotemporal Degener 2013;14(4):308-314.

54. Gauderer MW, Ponsky JL, Izant RJ. Gastrostomy without laparotomy: a percutaneous endoscopic technique. J Pediatr Surg 1980; 15(6):872-875.

55. Bach JR, Upadhyaya N. Association of need for tracheotomy with decreasing mechanical in-exsufflation flows in amyotrophic lateral sclerosis: a case report. Am J Phys Med Rehabil, in press.

56. Anderson T, Sandnes A, Brekka AK, Hilland M, Clemm H, Fondenes $\mathrm{O}$, et al. Laryngeal response patterns influence the efficacy of mechanical assisted cough in amyotrophic lateral sclerosis. Thorax 2016 [Epub ahead of print] doi: 10.1136/thoraxjnl-2015-207555. 